\title{
Argumentar por escrito en el discurso académico español ${ }^{1}$
}

Argument in writing in the Spanish academic discourse

Argumenter par écrit dans le discours académique espagnole

\section{Ángel Cervera Rodríguez²}

Recibido: 21 de abril de 2020

Aprobado: 27 de junio de 2020

Publicado: 3 de agosto de 2020

Cómo citar este artículo:

Cervera Rodríguez, Á. Argumentar por escrito en el discurso académico español.

Rastros Rostros, 21(1), 1-32.

doi: https://doi.org/10.16925/2382-4921.2019.01.04

Este artículo se inscribe en el proyecto del grupo de investigación Lingüística Aplicada del Español, 930507, adscrito al Dpto. de Lengua Española y Teoría de la Literatura, Facultad de Filología y subvencionado por el Banco de Santander, la Comunidad de Madrid y la Universidad Complutense de Madrid. https://doi.org/10.16925/23824921.2019.01.04

2 Doctor en Filología. Docente e investigador. Profesor titular en Facultad de Filología, Dpto. de Lengua Española y Teoría de la Literatura, Universidad Complutense de Madrid.

Correo electrónico: cervera1@filol.ucm.es

ORCID: https://orcid.org/0000-0003-3403-2708. 


\section{Resumen}

Introducción: las principales competencias que han de adquirir los estudiantes a lo largo de su formación son la comprensión lectora, la interpretación comunicativa y la producción discursiva mediante una expresión correcta, razonada y coherente. De esa forma, han de saber argumentar con criterios lógico-racionales en cualquier ámbito discursivo, sobre todo en el académico. Por medio de la argumentación pretendemos transmitir el conocimiento adquirido con criterios válidos, aunque podemos aportar ideas sobre el tema desde nuestro punto de vista utilizando razones sólidas que logren convencer a quienes nos dirigimos.

Metodología: el contenido del artículo se apoya en un marco teórico relevante de la lingüística del texto y el análisis del discurso, acompañado de un método analítico cualitativo aplicado a una selección de fragmentos de ensayos representativos, cuyo objetivo es reconocer y explicar los elementos lingüísticos, los recursos retóricos y los procedimientos pragmático-argumentativos del discurso académico con el fin de saber utilizarlos en las producciones discursivas.

Resultados: a través del análisis empírico y cualitativo aplicado a los ensayos seleccionados se comprueba que son textos apropiados para el discurso académico por estar dotados de organización lógica y por dominar en ellos la argumentación, la intertextualidad y la polifonía.

Conclusión: así pues, el ensayo es el prototipo de género discursivo académico español para desarrollar las competencias lingüístico-cognitivas y pragmático-comunicativas de los estudiantes.

Palabras clave: análisis del discurso, argumentación, discurso académico, ensayo, intertextualidad y pragmática.

\section{Abstract}

Introduction: The main competences to be acquired by students throughout their training are reading comprehension, communicative interpretation and discursive production through correct, reasoned and coherent expression. In this way, they must know how to argue with logical-rational criteria in any discursive field, especially in the academic sphere. Through the argumentation we intend to transmit the knowledge acquired with valid criteria, although we can contribute ideas on the subject from our point of view using solid reasons that manage to convince those we address.

Methodology: The content of the article is based on a relevant theoretical framework of text linguistics and discourse analysis, accompanied by a qualitative analytical method applied to a selection of fragments of representative essays, whose aim is to recognize and explain the linguistic elements, rhetorical resources and pragmatic-argumentative procedures of academic discourse in order to know how to use them in discursive productions.

Results: Empirical and qualitative analysis applied to the selected essays shows that they are appropriate texts for academic discourse because they are endowed with logical organization and because they dominate argumentation, intertextuality and polyphony.

Conclusion: Thus, the essay is the prototype of the Spanish academic discursive genre to develop the linguistic-cognitive and pragmatic-communicative competences of students.

Keywords: Discourse analysis, argumentation, academic discourse, essay, intertextuality and pragmatic.

\section{Resumo}

Introdução: As principais habilidades que os alunos devem adquirir ao longo de seus treinamentos são: compreensão de leitura, interpretação comunicativa e produção de discurso por meio de expressões corretas, fundamentadas e coerentes. Dessa forma, eles devem saber argumentar com critérios lógico-racionais 
em qualquer campo discursivo, especialmente na esfera acadêmica. Por meio de argumentação, tentamos transmitir o conhecimento adquirido com critérios válidos, embora possamos contribuir com idéias sobre o assunto do nosso ponto de vista, usando razões sólidas que conseguem convencer aqueles a quem estamos nos dirigindo.

Metodologia: O conteúdo do artigo é sustentado por um referencial teórico relevante da lingüística do texto e pela análise do discurso, acompanhado por um método analítico qualitativo aplicado a uma seleção de fragmentos de ensaios representativos, cujo objetivo é reconhecer e explicar os elementos linguísticos, os recursos retóricos e os procedimentos pragmático-argumentativos do discurso acadêmico para saber como utilizá-los em produções discursivas.

Resultados: Por meio da análise empírica e qualitativa aplicada aos ensaios selecionados, verifica-se que são textos adequados ao discurso acadêmico, por serem dotados de organização lógica e por dominarem argumentação, intertextualidade e polifonia.

Conclusão: Assim, o ensaio é o protótipo do gênero discursivo acadêmico espanhol para desenvolver as habilidades linguísticas-cognitivas e pragmáticas-comunicativas dos alunos.

Palavras-chave: Análise do discurso, argumentação, discurso acadêmico, ensaio, intertextualidade e pragmatica.

\section{Introducción}

La argumentación es una modalidad discursiva esencial para la relación interpersonal que está presente en cualquier tipo de discurso, especialmente en todo aquel que trata de mostrar conocimientos o verificar y demostrar experimentaciones e ideas, como en el académico y el científico. El acto de argumentar consiste en defender una idea o una opinión aportando razones que justifiquen nuestra postura, como señala Weston, 2004), al decir que "los argumentos son intentos de apoyar ciertas opiniones con razones" (p. 13), siguiendo la idea de Anscombre y Ducrot (1994) que consideran que "el valor de argumentativo está descrito mediante un acto ilocutorio, el de argumentar" (p. 27). Así, la argumentación se construye con ideas expresadas de manera coherente y argumentos sólidos que contribuyen a convencer a quienes nos dirigimos. Según esto, todos los hablantes tratamos de dotar a nuestros discursos de un razonamiento lógico y consistente con una orientación interactiva. En general, la argumentación está de algún modo presente en distintos ámbitos comunicativos sociales, profesionales, periodísticos, publicitarios, jurídicos, científicos, académicos, etc. Dentro de ellos, el académico presenta variaciones en el modo de construir la argumentación.

El objetivo que pretendemos con este trabajo es conocer las estrategias argumentativas y, a su vez, explicar los mecanismos lingüísticos, los recursos retóricos y los procedimientos pragmático-argumentativos característicos del discurso académico español. Para ello, hemos tomado como referencia de estudio y análisis el 
ensayo, considerado como un género abierto a la reflexión, a la transmisión de conocimientos, a temas, enfoques, opiniones, valoraciones, comparaciones y contrastes. Todo ello unido a que el ensayo constituye un discurso argumentativo (Cervera, 2019), puesto que las ideas que se defienden dependen de la experiencia, los conocimientos, las competencias y los valores con los que cuenta el locutor al dirigirse al destinatario-intérprete. Este carácter argumentativo del ensayo permite al locutor (estudiante) relacionar lo concreto con las ideas abstractas y las generalizaciones mediante recursos lingüísticos y procedimientos retóricos y dialécticos para favorecer la proyección cognitiva y pragmática del pensamiento en el discurso académico escrito que se manifiesta en explicación, mostración, justificación, contraste y deducción interpretativa del lector (evaluador). Hay, por ello, una estrecha relación entre discurso académico y ensayo, tal como señala Gallardo (2005), al decir que "la monografía es una clase de texto o género perteneciente al discurso científico o académico" (p. 13) y añade que "se denomina monografía tanto a un ensayo o una recopilación de información como a un verdadero trabajo de investigación donde se demuestra una hipótesis", aunque se diferencian en que, mientras el ensayo es un comentario libre sobre un tema, la monografía requiere mayor rigor teórico. De cualquier forma, el ensayo es un cauce adecuado para la transmisión del conocimiento académico, que abarca un conjunto amplio de clases textuales - monografía, comentario, resumen, conferencia, ponencia, artículo, manual, etc.-, que responden a las necesidades comunicativas que se desarrollan en el ámbito académico por parte de estudiantes, profesores e investigadores. Para afianzar nuestra investigación, hemos recurrido a cuatro ensayos de temas y tratamientos distintos: Horas de invierno, de M. J. de Larra; Evolución de la cartografía, de J. Lugo Hubp; La medicina y nuestro tiempo, de G. Marañón e Historia como sistema, de J. Ortega y Gasset.

Para fundamentar el estudio, partimos de un marco teórico basado en investigadores relevantes de la lingüística del texto, el análisis del discurso y la retórica de la argumentación, como Adam (1992), Anscombre y Ducrot (1983), Moeschler (1985), Perelman y Olbrechts-Tyteca (1994), Plantin (1990,1998), Beaugrande y Dressler (1997), Toulmin (1958), van Dijk (1983), van Eemeren et al. (2006), Werlich (1979), Weston (2004), Portolés (1998), Ribas (2002), Vázquez (2001, 2005), Cervera (2014, 2019), entre otros. Todos ellos coinciden en que la argumentación se inserta en la relación interlocutiva y es una modalidad esencial para la transmisión del conocimiento adquirido e investigado. En todo momento, la teoría va acompañada de ejemplos para identificar la diversidad de procedimientos que contribuyen a la producción de discursos. Asimismo, hemos complementado la teoría con aplicaciones prácticas recurriendo al ensayo como género discursivo argumentativo representativo para 
conocer la organización comunicativa y la transmisión del conocimiento y, a la vez, como prototipo referencial para cualquier producción discursiva en el ámbito académico. Para ello, hemos seleccionado un corpus integrado por cuatro fragmentos de obras relevantes de autores expertos en cada una de las áreas temáticas tratadas sobre la tarea de escribir de Larra, la evolución de la cartografía de Lugo Hubp, el ideal de escritor de Marañón y el concepto de historia de Ortega y Gasset. A partir de esta selección, hemos tratado de ajustar cada unidad textual al aspecto teórico desarrollado teniendo presente las operaciones cognitivas de comprensión e interpretación partiendo de la lectura comprensiva hasta llegar mediante el estudio analítico a la producción discursiva de la interpretación temática. Esta doble dimensión cognitiva-lingüística es la que va desde la lectura comprensiva de un texto ajeno a la expresión compositiva de un texto propio. Así pues, el análisis ha de ir dirigido a descubrir la macroestructura del texto y los componentes lingüístico-pragmáticos (Cuenca, 1995) y argumentativos (Vignaux, 1986) que tejen y proporcionan coherencia y unidad de sentido a cada texto. A través de este plan metodológico ahondamos el conocimiento adquirido tras la lectura para descubrir los procesos y representaciones que interactúan en el sistema cognitivo mostrado en el lenguaje textual.

\section{Marco de la argumentación en el discurso académico}

A la hora de afrontar una argumentación nos surgen muchas preguntas del tipo ¿qué procedimientos y técnicas podemos emplear al argumentar?, ¿cómo identificamos una argumentación?, ¿cómo distinguimos los argumentos veraces de los falaces? o ¿para qué y cómo argumentar? Y también nos podemos preguntar, más concretamente, por la frecuencia con la que empleamos expresiones atenuadoras: ¿pueden considerarse argumentativos los eufemismos? Ante esta pregunta, cabría razonar que por sí solos no son argumentativos, aunque son modos de expresión que sirven para minimizar, suavizar o reconducir el efecto de determinadas palabras e ideas y, a veces, se utilizan para construir argumentos innovadores o contraargumentos. A ello añadimos que son unas formas de expresión elegantes para hacer entender algo que podría resultar ingrato para alguno de los interlocutores. Así, en el enunciado, "Telefónica redujo la plantilla a través de un expediente de regulación de empleo (ERE) que afectó a muchos de sus trabajadores", se recurre a la expresión analítica expediente de regulación de empleo con carácter eufemístico para suavizar el mensaje, elidiendo palabras que contienen y connotan rasgos negativos sociales como paro laboral, echar a trabajadores. 


\section{Alcance conceptual de la argumentación}

La argumentación adquiere sentido dentro del discurso en general, teniendo en cuenta, como explican Beaugrande y Dressler (1997), que el uso del lenguaje es "la actividad humana más importante hecha discurso, por lo que nuestra conducta humana, más que lengua, es discurso" (p. 47), en el que está presente la intertextuali$\mathrm{dad}^{1}$. A ello puede añadirse que el discurso tiene sentido en la relación interlocutiva, es decir, a través del diálogo, como señala Carrillo (1997), al considerar que "argumentar es interaccionar, estructurando textualmente unos argumentos con la fuerza ilocutiva de su discurso" (p. 289). Más aún, puntualiza Álvarez (1997), que "argumentar consiste en aportar razones para defender una opinión o convencer a un receptor para que piense o actúe de una determinada forma" (p. 25). Por eso, la argumentación la dirige un locutor (o proponente) a un interlocutor (u oponente) para influir en él y persuadirlo, por lo que, de acuerdo con Jakobson (1975), la función lingüística propia dominante es la apelativa o conativa, puesto que se argumenta para los demás. En este sentido, la argumentación es una práctica discursiva orientada hacia el receptor (función apelativa) con el propósito de lograr su adhesión. A este respecto, Perelman y Olbrechts-Tyteca (1994) señalan que la pretensión de la argumentación es provocar, persuadir o acrecentar la adhesión a las tesis presentadas para su asentimiento. No obstante, en el discurso académico se busca que el conocimiento y las ideas transmitidas ofrezcan una garantía refrendada por el saber convencional propio de cada área de conocimiento, la experimentación y la experiencia compartida en el ámbito sociocultural y científico de que se trate. Ahora bien, los conceptos de "razón" y "argumento" no son idénticos, puesto que la razón está vinculada a la subjetividad (opinión), mientras que el argumento (prueba) lo constituye un conjunto de razones (premisas) que conducen a una conclusión, por lo que cabe decir que razonamos para nosotros y argumentamos para los demás interlocutores. Así la argumentación se inserta en el discurso dentro del ámbito sociolingüístico por su dimensión comunicativa interactiva, a la vez que desde una perspectiva psicolingüística el discurso responde a un proceso con orientación argumentativa que se manifiesta explícitamente en el texto como producto.

1 La intertextualidad es un concepto que permite reconocer la relación entre unos textos con otros al compartir conocimientos procedentes de la interacción comunicativa entre discursos. 


\section{La argumentación en el ensayo como discurso interactivo}

La argumentación es una modalidad habitual en el discurso oral y escrito, puesto que, al comunicarnos por vía oral (conversación, debate, coloquio, conferencia, disertación, ponencia, etc.) o escrita (discurso filosófico, científico, informativo, judicial, académico, etc.), nos dirigimos a alguien estableciendo una relación interlocutiva en la que ofrecemos opiniones y proporcionamos una visión del mundo y de la realidad sobre cualquier aspecto temático. A su vez, la argumentación es especulativa en cuanto a que parte de hechos sobre los que formulamos hipótesis que tratan de explicar una tesis con argumentos convincentes $\mathrm{y}$, además, como explica Plantin (1998), es dialéctica; puesto que su lenguaje no es un lenguaje de objetos, sino uno hablado por los interlocutores, marcado por sus puntos de vista, que se manifiesta mediante procedimientos pragmático-discursivos como la concatenación lógica (causa-efecto) y el contraste de ideas. Por ello, la modalidad argumentativa es apropiada para textos científicos y humanísticos sobre los que se centra el discurso académico y el ensayo para aproximarlo al científico. A este respecto, van Dijk (1983) puntualiza que "la estructura básica del discurso científico no solo consiste en una conclusión y su justificación, sino también en un planteo del problema y una solución" (p. 164), por lo que aúnan la argumentación y la explicación. En este sentido, el ensayo constituye el marco de referencia del discurso académico, ya que, como dice Álvarez (1997), "el ensayo es uno de los cauces habituales a través del que se manifiestan la exposición y la argumentación" (p. 25). Es, pues, un género discursivo que sirve de instrumento adecuado para mostrar ideas y conocimientos tanto socioculturales como científicos, por lo que se convierte en referencia idónea para el discurso académico en sus diversas manifestaciones: resumen, comentario, examen, conferencia, monografía, informe o artículo. Además, el ensayo, como señala Cervera (2019), "es un discurso integrador en cuanto a que participa de temas de las diversas materias o disciplinas y utiliza formas de expresión, metodologías y procedimientos del resto de géneros" (p. 22), por lo que sirve de cauce de transmisión del conocimiento en toda su extensión. 


\section{La argumentación en el marco expositivo del discurso académico}

Las diferentes formas de presentarse el discurso académico comparten con el ensayo las tres modalidades textuales -exposición, argumentación y explicación-2, aunque no siempre concurren en el mismo texto. Se trata de unidades discursivas de producción comunicativa - oral y escrita- que tienen en común una organización semejante al modelo expositivo-argumentativo - presentación o parte introductoria, cuerpo o parte central y conclusión o parte final-, aunque los objetivos son distintos. Para Ribas (2002), explicar y argumentar son acciones lingüísticas, por lo que en la mayor parte de los discursos suelen concurrir técnicas comunes de la modalidad explicativa y argumentativa, además de la ordenación secuenciada y jerarquizada de la información, como la definición para delimitar los conceptos; la clasificación para señalar las partes o características de un tema; la reformulación para explicar de forma clara lo expresado mediante indicadores metalingüísticos: "es decir, esto es, a saber, en otros términos, con otras palabras, más exactamente"; la ejemplificación, para concretar lo abstracto mediante los indicadores "por ejemplo, como, pongo por ejemplo", etc.; la analogía para relacionar los objetos mediante comparaciones y las referencias y las citas de autoridad para avalar la propuesta.

Todas estas estrategias de carácter argumentativo y explicativo se utilizan indistintamente en el discurso académico y en el ensayo: la exposición constituye el marco informativo; la explicación, que tiene una base expositiva, persigue la claridad comprensiva y una finalidad demostrativa y la argumentación es una modalidad habitual en el discurso oral y escrito en el que interactúan, como dice Lo Cascio (1998), un locutor (o proponente), cuyo propósito (función) es defender el objeto temático (tesis) con argumentos y estrategias que convenzan al alocutor (o interlocutor intérprete y oponente), quien puede aceptar, objetar o rechazar mediante contraargumentos. Esto mismo se recoge en Werlich (1979), al decir que en la argumentación se pretende persuadir al interlocutor a que participe del punto de vista del locutor (opción positiva) a la vez que trata de disuadir de otras posiciones (opción negativa). Por ello, en el discurso académico hemos de utilizar la argumentación para lograr que las ideas

2 La argumentación, la exposición y la explicación son tres modalidades textuales que requieren claridad, orden y objetividad en el desarrollo de las ideas en torno a un tema. $Y$, aunque pueden concurrir en un mismo discurso, son diferentes: la exposición transmite información, muestra hechos, al tiempo que se dan a conocer ideas con un enfoque objetivo y un desarrollo lógico; en la explicación se presentan las ideas con una finalidad clarificadora y didáctica, basadas principalmente en la propuesta de problema-solución; y en la argumentación se pretende persuadir al interlocutor a que participe del punto de vista del locutor (opción positiva) a la vez que trata de disuadir de otras posiciones (opción negativa). 
expresadas convenzan al destinatario y prever los contraargumentos y réplicas en la interpretación. La argumentación, como explican Cervera et al. (2007), "consiste en apoyar y defender una idea planteada con claridad y firmeza e intentar convencer a otro de una idea" (p. 379). Es, por ello, una modalidad textual que está presente no solo en los textos académicos y científicos, sino en casi todos los actos de comunicación. En esta línea, Calsamiglia y Tusón (1999) puntualizan que "la argumentación es una práctica discursiva que responde a una función comunicativa: la que se orienta hacia el receptor para lograr su adhesión" (p. 294).

\section{Estructura y construcción del discurso académico}

Los textos generados en el ámbito académico están constituidos por una estructura externa, unida a la distribución de secciones, epígrafes y párrafos marcados por los puntos y aparte, y la interna, referida a la organización o disposición de las ideas de forma deductiva o inductiva. En líneas generales, la estructura del ensayo se corresponde con la del texto argumentativo, como explica Weston (2004), puesto que normalmente está constituido por la introducción, donde se plantea el tema o tesis, se enuncian los hechos y se proponen las hipótesis; el cuerpo argumentativo, donde se explican las causas, ideas o hechos con argumentos objetivos para justificar o demostrar la defensa de la tesis; y la conclusión, donde se extraen las consecuencias de la demostración ya deductiva, sintetizando las ideas de los argumentos que avalan la tesis, ya inductiva, formulando la tesis tras el razonamiento.

Los argumentos son las razones en las que basamos nuestra postura sobre la tesis planteada hasta llegar a la conclusión. El procedimiento argumentativo más característico es el silogismo, entendido como un razonamiento de carácter deductivo que llega a una conclusión a partir de dos afirmaciones Ilamadas premisas. Estas premisas son proposiciones lingüísticas de valor verdadero o falso. A diferencia del silogismo, el paralogismo no es un razonamiento aceptable, por lo que se convierte en sofisma, donde falla alguna de las premisas o la conclusión. Con frecuencia se utilizan los sofismas para atacar al oponente (ad hominem), como la ignorancia. Dentro de los silogismos, el entimema es un silogismo al que le falta alguna parte, generalmente la premisa menor. Por ejemplo: "Todos los veranos son calurosos, por lo que nos vamos a la playa" (falta la premisa: "Este verano es caluroso"). La estructura argumentativa está marcada normalmente por indicadores lingüísticos, que, a su vez, suelen relacionarse con el desarrollo argumental. Tratamos, pues, de explicar la estructura y la 
construcción del discurso académico partiendo de un texto representativo extraído del artículo "Horas de invierto" de Larra (2000)3 sobre la tarea de escribir, en el que contrasta la diferencia de escribir en Francia y en España:

Escribir y crear en el centro de la civilización y de la publicidad, como Hugo y Lherminier, es escribir. Porque la palabra escrita necesita retumbar, y como la piedra lanzada en medio del estanque, quiere llegar repetida de onda hasta el confín de la superficie; necesita irradiarse, como la luz, del centro a la circunferencia. Escribir como Chateaubriand y Lamartine en la capital del mundo moderno es escribir para la humanidad, digno y noble fin de la palabra del hombre, que es dicha para ser oída. Escribir como escribimos en Madrid es tomar una apuntación, es escribir en un libro de memorias, es realizar un monólogo desesperante y triste para uno solo. Escribir en Madrid es Ilorar, es buscar voz sin encontrarla, como en una pesadilla abrumadora y violenta. Porque no escribe uno siquiera para los suyos. ¿Quiénes son los suyos? ¿Quién oye aquí? ¿Son las academias, son los círculos literarios, son los corrillos noticieros de la Puerta del Sol, son las mesas de los cafés, son las divisiones expedicionarias, son las pandillas de Gómez, son los que despojan, o son los despojados? (Larra. 2000).

Aun siendo breve el texto de Larra que presentamos, el contenido es sólido, razonado y justificado por el conocimiento de la literatura francesa y su experiencia personal de la sociedad de Madrid en la que vive. Observamos que presenta un orden deductivo, pues centra su núcleo temático en la tarea de escribir. Los recursos lingüísticos -léxicos, sintácticos y semánticos - están al servicio de la crítica de escribir en Madrid, que le defrauda y le angustia. Por eso manifiesta la diferencia que existe entre escribir en Francia, donde los escritores lo hacen para la humanidad, y en España, Madrid, donde no se escribe para nadie. El texto está integrado por enunciados oracionales de modalidad enunciativa. Comienza con un enunciado asertivo expresado de forma tautológica: "Escribir y crear [...] es escribir" con una explicación intercalada a modo de ejemplo identificativo "como Hugo y Lherminier". Sigue una serie de enunciados con fines explicativos donde se comparan y contrastan las dos formas de escribir que propone: la de Francia, destinada a la humanidad, y la de Madrid, que es

3 Mariano José de Larra (1809-1827) fue un ensayista de numerosos artículos como "Vuelva usted mañana", "El casarse pronto y mal", "La nochebuena de 1836", "El casteIlano viejo", "Yo quiero ser cómico", "Literatura", "El café", etc., con un estilo nuevo considerado como el creador del periodismo moderno. Escribió también cuatro sonatas: la de primavera, de estío, de otoño y de invierno, en estilo modernista. 
inútil. La explicación inicia con el conector discursivo "porque" e incluye dos estructuras comparativas a modo de analogía "como la piedra lanzada en medio del estanque" y "necesita irradiarse, como la luz, del centro a la circunferencia".

A continuación, se agregan enunciados mediante la recurrencia léxica "escribir" y enunciados oracionales enunciativos en estructuras atributivas con la idea de comparar y contrastar, a juicio del escritor, las dos formas de escribir en Francia y España: "Escribir como Chateaubriand y Lamartine es escribir para la humanidad" y "escribir como escribimos en Madrid es tomar una apuntación [...]", con tres miembros yuxtapuestos o "escribir en Madrid es llorar", complementado con una puntualización comparativa. Y justifica esta última afirmación con una explicación basada en una visión pesimista, por lo que recurre de nuevo al conector causal "porque" iniciando un enunciado negativo, al que siguen otros enunciados vinculados por el posesivo con valor deíctico "suyos" en forma de interrogaciones directas donde presenta duda y ambivalencia impregnadas de perplejidad y pesimismo.

\section{Los argumentos en el discurso académico}

En la argumentación se contempla la doble posibilidad de confirmar o avalar una teoría mediante pruebas que la justifiquen y de refutar la falsedad o la falta de rigor de una idea con razonamientos firmes y coherentes (garantías). Anscombre y Ducrot (1994) tratan de diferenciar entre "el acto de argumentar, que se realiza a partir de la propuesta y demostración y el valor argumentativo, referido a los enunciados que en el discurso conducen a una conclusión mediante operadores y conectores discursivo-argumentativos" (p. 27). En realidad, la lengua es fundamentalmente argumentativa, en cuanto a que el significado de las oraciones debe comportar indicaciones respecto al valor argumentativo del enunciado-ocurrencia, aunque puede ser una indicación de dirección, no de conclusión. De cualquier forma, en la argumentación concurren al menos dos tipos de enunciados, uno es el enunciado-argumento y el otro, el enunciado-conclusión.

\section{Argumentos consistentes y válidos en el discurso académico}

Normalmente en la argumentación las premisas se presentan de forma implícita o explícita mediante frases que afirman o niegan algo, que vienen a dar cuenta de datos (observaciones constatadas) o bien a establecer garantías (justificación de los datos señalados). Para ello, el locutor en el discurso ha de recurrir a argumentos racionales 
que sirvan para verificar y demostrar la tesis o el tema planteado. Son válidos los siguientes argumentos:

- lógico-deductivos: responden a argumentos inferenciales, en los que, como dice Weston (2004), "la verdad de sus premisas garantiza la verdad de sus conclusiones" (p. 79), aunque se presentan de varias formas, como aparecen en la figura 1.

\begin{tabular}{|c|c|c|}
\hline $\begin{array}{l}\text { Argumentos } \\
\text { lógico-deductivos }\end{array}$ & $\begin{array}{l}\text { Conceptos } \\
\text { inferenciales }\end{array}$ & Ejemplos \\
\hline Modus ponens & $\begin{array}{l}\text { Lo afirmado en las } \\
\text { premisas se afirma en la } \\
\text { conclusión. }\end{array}$ & $\begin{array}{l}\text { La biología estudia la vida (si p), entonces estudia las } \\
\text { células de los seres vivos (entonces q), por tanto, la } \\
\text { biología estudia las células de los seres vivos. }\end{array}$ \\
\hline Modus tollens & $\begin{array}{l}\text { Lo negado en las premisas } \\
\text { se niega en la conclusión. }\end{array}$ & $\begin{array}{l}\text { Si no existe el mal, no existe el bien (si p entonces q), no } \\
\text { existe el bien (no q), por tanto, no existe el mal (luego } \\
\text { no-p). }\end{array}$ \\
\hline Hipotético & $\begin{array}{l}\text { Cumple este esquema: } \\
\text { si p entonces q. } \\
\text { Siempre que la "q" de } \\
\text { una premisa cambie en la } \\
\text { siguiente. }\end{array}$ & $\begin{array}{l}\text { Si se construye mucho en la costa, se deteriora el litoral } \\
\text { (si p entonces q), si el litoral se deteriora mueren especies } \\
\text { marinas (si q entonces r); por tanto, si se construye en la } \\
\text { costa mueren especies (por tanto, p entonces r). }\end{array}$ \\
\hline Disyuntivo & $\begin{array}{l}\text { Sigue este esquema: } \\
\text { po q } \\
\text { no-p } \\
\text { por tanto, q. }\end{array}$ & $\begin{array}{l}\text { Los males del mundo obedecen a la falta de ética o por un } \\
\text { mal uso de la inteligencia (p o q); el ser humano no ha en- } \\
\text { contrado métodos eficaces de ética (no p); luego hallarlas } \\
\text { es la mejor aplicación de la inteligencia (por tanto, q). }\end{array}$ \\
\hline $\begin{array}{l}\text { Dilema } \\
\text { Parte de una alter- } \\
\text { nativa, pero las otras } \\
\text { premisas muestran } \\
\text { que los dos casos } \\
\text { llegan a la misma } \\
\text { conclusión. }\end{array}$ & $\begin{array}{l}\text { Sigue este esquema: } \\
\text { po q } \\
\text { si p entonces r } \\
\text { si q entonces s } \\
\text { por tanto, ros. }\end{array}$ & $\begin{array}{l}\text { Se puede construir especulando o con racionalidad (p o } \\
\text { q), unos creen que hay que seguir por el empleo (si p en- } \\
\text { tonces r) y otros que hay que dejar de construir para evitar } \\
\text { la burbuja inmobiliaria (si q entonces s), lo cierto es que la } \\
\text { economía sufre por un lado y por otro (por tanto, r o s). }\end{array}$ \\
\hline
\end{tabular}

Figura 1. Tipos de argumentos lógico-deductivos

Fuente: basado en Weston, 2004.

A los tipos de argumentos de carácter lógico-deductivos de la figura 1, hay que añadir otros procedimientos argumentativos que contribuyen a dar validez y consistencia al discurso académico, entre ellos:

- Los de causa-efecto: establecen una relación de causa-efecto y al revés: "Suben los tipos de interés para hacer frente a la deuda y al déficit, pero también perjudica a los salarios/Bajan los tipos de interés para que la banca pueda ofrecer créditos". 
- Los de hecho, circunscritos a pruebas observables y constatables: "El terremoto y el tsunami que azotaron la bahía de Japón en 2011 resultaron catastróficos para el país".

- $\quad$ Los de ejemplificación, basados en ilustraciones y casos concretos: "En el pasado las mujeres se casaban muy jóvenes. En Romeo y Julieta ella no tenía catorce años. En la Edad Media las judías se casaban con 13 años y en el Imperio Romano incluso antes".

- Los de analogía o semejanza mediante comparaciones: "El teatro es como la vida misma, se escenifica".

- Los basados en la autoridad o el testimonio de expertos, especialistas y personas de reconocido prestigio mediante citas de obras o artículos de revistas en el ámbito temático de que se trate: científico, cultural, artístico, literario, histórico, filosófico, político, económico, musical, etc. A veces, estos argumentos pueden ser rebatidos apoyándose en otras teorías u otros especialistas. Con el argumento de autoridad se refuerza el argumentario del proponente (ante el cual oponente puede optar por callarse ad verecundiam, esto es, por vergüenza o por refutar o contraargumentar con otras referencias o citas. Según Weston (2004), las fuentes han de ser fiables asegurándose de que se cita correctamente y no está sacada fuera de contexto. Así sucede, por ejemplo, a las palabras de Salinas (1992) al referirse a la lengua oral y escrita: "de la lengua hablada, se nutre, se fortifica la lengua escrita, sin cesar, y de ella suben energía, fuerzas instintivas del pueblo, a sumarse a las bellezas acumuladas de la lengua escrita" (p. 31).

- Las definiciones en forma de asertos: "El hombre es la medida de todas las cosas, en palabras del sofista Protágoras" o Toda discusión sobre la democracia (demos=pueblo; cracia=gobierno) Ileva a plantearse la diferencia que existe entre democracia representativa (se delega por 4 años el poder en el candidato votado) y la democracia participativa.

- Los datos obtenidos de pruebas y experimentaciones, pero también de estadísticas basadas en muestreos y metodologías científicas: "Según el Instituto de la mujer, la mayoría de las mujeres no denuncia las agresiones que sufren".

- Los argumentos basados en el conocimiento contrastado y la verdad evidente, como "Fumar es perjudicial para la salud, por lo que la OMS recomienda dejar de fumar". 
Ahora bien, ¿cómo se articulan los argumentos válidos en un discurso académico? Para ello, hemos seleccionado un texto de conocimiento sobre la evolución de la cartografía de Lugo Hubp (2016) en una línea didáctica propia de los manuales académicos:

Los mapas temáticos tienen su antecedente en Tolomeo, quien los elaboró de tipo histórico. En forma aislada aparecieron desde el siglo XVIII mapas específicos para representar algún fenómeno de la naturaleza, además de los históricos que fueron los más comunes. En la segunda mitad de este siglo se popularizaron los términos mapa y cartografía temáticos y en esta época se han multiplicado en grado superlativo.

El mapa ha sido siempre un reflejo del estado de desarrollo de determinadas disciplinas científicas. Si actualmente hay decenas o cientos de mapas temáticos diversos, esto da una idea del estado actual de las geociencias. Uno de los más conocidos es el publicado en 1936 sobre la agricultura de EUA. Destacó por su originalidad. Posteriormente han sido editados mapas complejos en diversos países, resultado de investigaciones prolongadas e incluso multidisciplinarias, apoyadas por instituciones científicas y financieras.

Dice el geógrafo soviético Nicolay F. Leontiev: 'La cartografía temática actual es un documento fundamental de investigación para el científico, un instrumento absolutamente necesario en la elaboración de todos los proyectos posibles para el aprovechamiento de nuevos territorios y un medio para la comprensión del mundo que nos rodea'.

Todavía no se ha llegado a un estado de perfección de los mapas mundiales de tipo geográfico general. La tierra firme es bien conocida por fotografías aéreas e imágenes de satélite, además de observaciones y mediciones directas, pero el relieve submarino se ha cartografiado a partir de mediciones indirectas. En términos generales, puede decirse que es bien conocido el fondo oceánico y están en proceso de elaborarse nuevos mapas que van sustituyendo a los anteriores.

Los primeros mapas del relieve de los océanos Atlántico y Pacífico fueron muy simples; sin embargo, ameritaron su publicación en las revistas geológicas de mayor prestigio. Algo semejante pasa con los mapas de la Luna o los planetas cercanos a la Tierra: presentan una información muy 
general y pobre en extremo, en comparación con algún mapa equivalente de nuestro planeta. Pero nadie puede negar el inmenso valor de esa información. (Lugo Hubp, 2016).

El texto se centra en la cartografía y su evolución. Al leer el texto de Lugo Hubp, observamos la armonización temática centrada en la cartografía y su evolución, en la que se combina la argumentación con la exposición y la explicación. Al mismo tiempo, hemos de reconocer los argumentos a los que recurre el autor para dar validez a las ideas expuestas fijándonos expresamente en la palabra clave y la técnica especializada del tema. El enfoque del tema es objetivo y el tratamiento es de carácter informativo, cuyo contenido se desarrolla de forma inductiva, sucesiva o cronológica y recurrente mediante la repetición de "mapa". Toma como base la modalidad expositiva en la transmisión de la evolución histórica de los mapas, a la que acompañan la explicativa al tratar de clarificar y diferenciar los mapas generales de los particulares y la argumentativa al tratar de demostrar la tesis planteada en forma de aserto en el $2^{\circ}$ párrafo: "El mapa ha sido siempre un reflejo del estado de desarrollo de determinadas disciplinas científicas". Para lograrlo, recurre a la definición, basándose en una cita de autoridad: "Dice el geógrafo soviético Nicolay F. Leontiev: La cartografía temática actual es un documento fundamental de investigación para el científico"; a las referencias históricas, geográficas y temáticas, como "Tolomeo, s. XVIII, Tierra, océano Atlántico y Pacífico, Luna, planeta, mapas mundiales"; a la clasificación, al diferenciar mapas generales, específicos y temáticos; a la reformulación, al utilizar términos sinónimos como: "En la segunda mitad de este siglo se popularizaron los términos mapa y cartografía temáticos"; a la ejemplificación, al referirse a los tipos de mapas temáticos: "Uno de los más conocidos es el publicado en 1936 sobre la agricultura de EUA"; y a la analogía, al comparar los mapas de los planetas con los de la Tierra con estas palabras: "Algo semejante pasa con los mapas de la Luna o los planetas cercanos a la Tierra: presentan una información muy general y pobre en extremo, en comparación con algún mapa equivalente de nuestro planeta".

Y, para afianzar y reforzar el sentido argumentativo, el autor recurre a la explicación complementaria; a la recurrencia léxico-semántica "mapa, geógrafo, cartografía"; a actualizadores temporales "actualmente, posteriormente, todavía"; y a marcadores discursivos: generalizadores "en términos generales"; aditivos "además de; contrastivos "sin embargo, pero", puntualizadores particulares causativos "por la originalidad"; e intensivos "e incluso multidisciplinarias". Finaliza con un aserto apelativo general a modo de conclusión o corolario: "Nadie puede negar el inmenso valor de esa información". Maneja el autor un vocabulario temático propio de la cartografía junto a palabras 
genéricas y abstractas acompañadas de adjetivos especificativos como corresponde a un texto especulativo y analítico; de ahí que la palabra clave sea "mapa y cartografía" y la palabra técnica especializada más característica es "geociencia", al relacionar el estudio de los mapas con el estado actual de las geociencias.

\section{Argumentos poco consistentes en el discurso académico}

Existen argumentos que pueden aceptarse si se utilizan como complemento de un razonamiento coherente, aunque no tienen la misma consistencia que los analizados en el epígrafe anterior. Nos referimos a argumentos apoyados en la experiencia colectiva mediante aserciones compartidas, como "El mundo es imperfecto"; en la generalización, mediante la utilización de un hecho concreto tomado como representativo de situaciones generales. Álvarez (1997) puntualiza que, en ocasiones, pueden integrarse en este grupo también el uso de proverbios y refranes pues en ellos se refleja una "verdad" conocida y comúnmente aceptada: "Es difícil contentar a todo el mundo, porque no siempre llueve a gusto de todos"; en creencias generales o comunes, como "Nada es casual" o "Todo tiene una razón de ser"; en normas, como "El carnet es el documento de identificación obligatorio"; en valores, como "Más vale honra sin barcos que barcos sin honra"; en objetivos, como "El corazón debe ablandarse con los más débiles"; en la utilidad: "Afrontar el calentamiento de la Tierra nos ayudará a todos"; en la ética: "Ayudar a los inmigrantes a integrarse es de exigencia moral, aunque no lo contemple la ley"; y en la visión hedonista, sustentada en el tópico del placer o de la felicidad circunstancial: "Hay jóvenes a quienes les gusta salir hasta las tantas y beber sin moderación ni control para sentirse bien".

\section{Argumentos inconsistentes y/o falaces}

En numerosos textos se recurre a argumentos que carecen de consistencia argumental válida. Anscombre y Ducrot (1994) explican el papel de los topoi, que "son creencias presentadas como comunes a cierta colectividad de la que al menos forman parte el locutor y su alocutor" (p. 218), que supone que las comparten. Al presentarse de manera general, el topoi tiene validez en muchas situaciones, pero no siempre. A esto es a que Lo Cascio (1998) Ilama "argumentos falsos o falaces" (p. 291), recurriendo al juego lingüístico o fuera de lo lingüístico, manipulando los hechos. Por su parte, Weston (2004) considera que "las falacias son errores, errores en los argumentos" (p. 123). Es importante, pues, reconocer, al leer o construir un 
texto, los procedimientos que adquieren validez argumentativa, pero también debemos identificar y controlar todo lo que carece de valor argumentativo en el discurso académico, como expresar la propia opinión sin más en expresiones del tipo "Así lo entiendo yo, eso es lo pienso, así lo creo", carentes de consistencia argumental. A ello hay que añadir la amplia variedad de falacias, que contienen errores lógicos, lo que lleva a invalidar el razonamiento y la validez de la conclusión. Así observamos con frecuencia en muchos textos la utilización de datos escasos y vagos, no probados: "Mañana va a llover por lo que han dicho"; la apelación a la piedad o compasión: "No me dejes aquí, soy tu amigo"; la referencia a la mayoría: "Todo el mundo lo hace así"; la afirmación de la consecuencia sin presentar la causa: "Si llueve, las calles se mojan/ las calles están mojadas, ha llovido"; el uso de expresiones emotivo-despreciativas: "Es un poco testarudo, sin ofender"; la falsa autoridad: "Este producto de belleza lo avala la mejor fábrica de cosméticos del mundo"; la argumentación ad hominem intentando demostrar que algo es falso desacreditando a quien lo ha dicho: "No hagas caso de lo que dice ese autor, no sabe nada del tema"; la casuística, tomando como regla un caso excepcional: "La justicia no funciona porque en esta sentencia se ha dado validez a una prueba inexistente"; la confusión de causas: "Trabaja mucho, luego gana mucho dinero"; la formulación de preguntas múltiples en una misma propuesta: "¿Estás de acuerdo con el pacto de Estado de la Educación y con la obligatoriedad de Educación para la ciudadanía?"; la elusión de un asunto que parece querer demostrar, pero lo evita: "La reforma laboral es prioritaria, pero ahora interesa hablar de otro tema"; el equívoco, que se comete cuando un término es usado más de una vez dentro de un mismo enunciado pero con significados totalmente distintos: "La rosa no siempre es rosa"; y la causa falsa, que se comete al aceptar conclusiones que se basan en supersticiones y creencias, como "Hoy tendré un buen día en los negocios porque mi horóscopo lo dice".

\section{La fuerza de los argumentos en el discurso académico}

La argumentación es, ante todo, interactiva, por lo que ha adquirido pleno sentido histórico desde la antigüedad en géneros orales como la oratoria, el debate, la conferencia, la ponencia o la disertación, pero también en cualquier género discurso escrito donde están presentes -explícita o implícitamente- un locutor (escritor) y un alocutor (destinatario intérprete). Aunque Marafioti (2005), siguiendo a Toulmin, (1958), solo habla de cinco campos argumentativos: jurídico, científico, artístico, empresarial y ético. Sin embargo, la argumentación es esencial también en el discurso periodístico, 
el ideológico, el parlamentario, el publicitario y el académico, con proyección teórica, didáctica, analítica, crítica e investigadora.

En el discurso académico es fundamental la utilización de argumentos sólidos y la utilización de referencias inequívocas y fuentes fiables reconocidas culturalmente. A través de los argumentos el locutor procura no solo convencer al lector intérprete, sino también influir y orientarle en su pensamiento, sus ideas y actuaciones para la obtención de una valoración positiva. Para ello, hemos de controlar las operaciones lingüístico-cognitivas que se desencadenan en el discurso argumentativo mediante una propuesta de premisas y un desarrollo de argumentos que lleven a una conclusión válida, como señala Plantin (1998), con el fin de que destinatario acepte la tesis por las razones que llevan a la conclusión. Así se presenta un esquema argumentativo progresivo, en el que se integran los argumentos en relación con el objeto, el lenguaje y la interacción, como aparece en la figura 2.

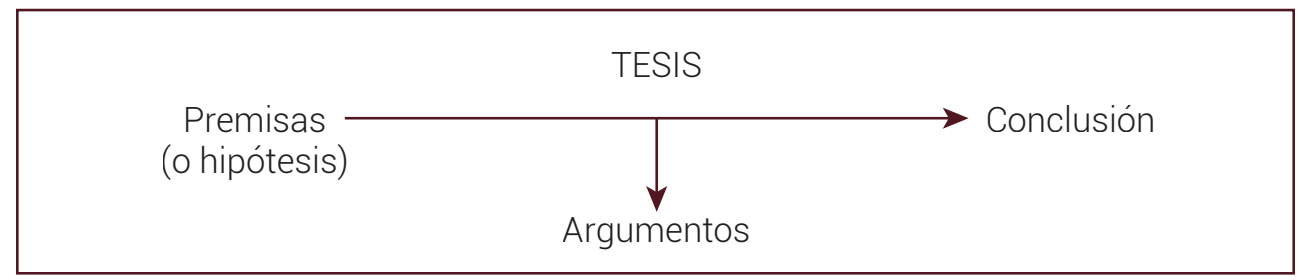

Figura 2. Esquema del proceso argumentativo

Fuente: Plantin, 1998.

Tal como se ven en la figura 2, las premisas o hipótesis constituyen los fundamentos del razonamiento, que responden a principios -implícitos o explícitos - representados en el desarrollo argumentativo con miras a lograr una conclusión válida. Ya la retórica clásica distinguía argumentos en relación con las personas y las cosas recurriendo a la definición, semejanza o analogía, comparación, suposición y circunstancia, además de los lugares comunes o topoi. van Dijk (1983) mantiene la idea de que "la estructura del texto argumentativo puede seguir analizándose más allá de las categorías convencionales de hipótesis y conclusión" (p. 159), pero introduce la categoría de "legitimidad o garantía", complementando el modelo argumentativo de Toulmin (1958) para pasar a la conclusión, como se muestra en la figura 3. 


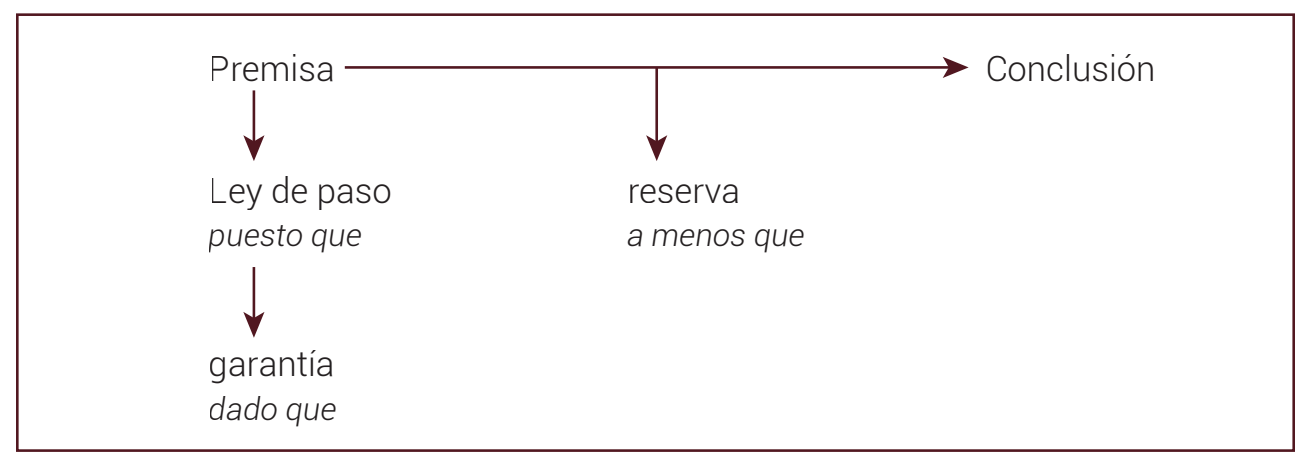

Figura 3. Esquema de ley de paso en el proceso argumentativo

Fuente: Toulmin, 1958.

Esta relación puede estar fundamentada explícita o implícitamente (ley de paso y garantía) o bien ser refutada o restringida (reserva). En todo caso, dice Lo Cascio (1998), el marco argumentativo en el discurso se concreta en el tema, el contexto y los interlocutores, a los que hay que añadir el género, el propósito del locutor, el argumentario y el grado de convicción derivada de la interpretación del destinatario.

\section{Procedimientos lingüístico-pragmáticos en el discurso académico}

El texto argumentativo es un tipo de discurso que se fundamenta en dar motivos y razones para defender o rebatir un punto de vista, pero también para convencer a un interlocutor de una idea por medio de un razonamiento convincente. van Eemeren et alii (2006) proponen cuatro tipos diferentes de estructuras argumentativas, que explican la complejidad de los textos argumentativos, mediante indicadores lingüísticos en forma de: argumento único, argumento múltiple, argumentación coordinada y argumentación subordinada. Por esta razón, el locutor de un texto perteneciente al discurso académico suele utilizar los recursos lingüísticos y los procedimientos pragmático-discursivos con el fin de lograr que el destinatario dé validez y valore positivamente las ideas desarrolladas.

\section{Recursos lingüísticos y retóricos en el discurso académico}

Normalmente, la selección de los elementos lingüísticos ha de ponerse al servicio del enfoque que deseamos ofrecer en el producto discursivo que vamos a elaborar, que 
puede ser subjetivo, cuando recurrimos a presupuestos, a la experiencia personal y a la expresividad en textos literarios y periodísticos o de opinión, o bien objetivo, dominante en textos científicos y demostrativos que requieren de una argumentación sólida contrastable y comprobable, aunque puede darse también en humanísticos, periodísticos, jurídicos, etc., siempre que el propósito sea proyectar el tema con objetividad inequívoca.

El discurso argumentativo por excelencia es el discurso retórico. Desde Aristóteles, la retórica es el arte del discurso persuasivo, es una técnica que enseña a elaborar discursos cuyo objetivo es persuadir a los interlocutores a quienes se dirige un locutor. Según señala Marimón (2006), la frase básica de la argumentación responde al esquema: No + SER (presente) + SN, donde la negación se convierte en un elemento caracterizador del argumento; por ejemplo, frente a la idea de que "La guerra es una solución contra el terrorismo", cabe argumentar lo contrario:" La guerra no es la única ni la mejor solución contra el terrorismo". Además, están presentes otros recursos gramaticales, como la modalidad oracional enunciativa e interrogativa; el dominio de la función apelativa para persuadir al receptor; la preferencia por los verbos dicendi, de causalidad y consecuencia; el predominio del presente y futuro de indicativo y condicional; el uso de la $3^{\mathrm{a}}$ persona para mostrar objetividad y $2^{\mathrm{a}}$ para la apelación; el estilo directo en las citas y preguntas retóricas; la utilización de estructuras oracionales simples (pasiva refleja, impersonal con o sin "se") y coordinadas; la preferencia por la modalidad oracional enunciativa para proporcionar objetividad, pero también se recurre a las modalidades exclamativa, interrogativa y exhortativa; el empleo de la sintaxis compleja para la relación causa-efecto por medio de la subordinación: hipotéticas, causales, concesivas, comparativas, finales y consecutivas; la contraposición de ideas mediante adversativas y concesivas; y la presencia de expresiones explicativas intercaladas.

A los recursos gramaticales se añaden componentes léxicos y semánticos de diversa índole, como el léxico especializado y preciso para evitar la ambigüedad o el equívoco; el establecimiento de contrastes léxico-semánticos, como "Ante el desacato a cumplir el orden constitucional, para unos una persona puede ser considerado como traidora a la patria y para otros, un héroe revolucionario"; el empleo de procedimientos retóricos, como las comparaciones, metáforas e hipérboles, antítesis o contraste, metonimia, paráfrasis o formas analíticas, paralelismo, amplificaciones, apóstrofes, correspondencias, juegos de palabras, etc.; y la utilización de argumentos por los contrarios: 'a es p', luego 'no-a es no p' (no tiene validez lógica real, pero crea argumentos plausibles), como vemos en este ejemplo: - “Cómo hacer que descienda el paro? Los países con tasas bajas de paro tienen despido libre. Si un país tiene tasas 
de paro altas y despido controlado, para tener tasas de paro bajas no debe tener despido controlado, sino despido libre" ("Los motivos para abaratar el despido", 2018). Al leerlo, observamos que utiliza un procedimiento en el que se identifican términos contrarios ("países con tasas bajas de paro=despido libre/país con tasas altas de paro=despido controlado"), creando la falsa impresión de una relación causal entre despido libre y tasas bajas de paro. Estos elementos, a su vez, se complementan con la utilización de los signos, símbolos y marcas gráficas que requiere la corrección ortográfica panhispánica.

De cualquier forma, para explicar la utilización de los elementos lingüísticos y retóricos al servicio de la transmisión del pensamiento razonado con proyección pragmática, proponemos un fragmento de Marañón (1969)4 sobre el ideal de escritor:

Pero hay todavía una última razón, entre las que a mí se me ocurren, que abona la utilidad de la diversión artística en los hombres de ciencia, y es la ventaja del uso literario del lenguaje para lograr la exacta expresión científica. Es evidente que un buen escritor, si es además un sabio, posee el instrumento de expresión de su sabiduría en mayor medida que el que escribe obscuramente. Y, en la ciencia, la forma con que se reviste la verdad forma parte de la verdad misma. No es, pues, cualidad accesoria, sino esencial. La verdad es, por sí misma, por definición, clara, y el arte de la claridad es, por consiguiente, factor científico de primera categoría. La mutua influencia entre la ciencia y el arte es doble. La literatura científica, que tiene que ser, por fuerza, exacta, diáfana, elemental, es el gran modelo para la retórica del escritor de oficio. Se ha dicho y es cierto, y yo lo he repetido muchas veces, que a ciertos literatos les curaría la redacción del pensamiento científico de su propensión a ser gárrulos e imprecisos. Pero es también importante la ventaja inversa, la que obtendrían los hombres de ciencia de una disciplina literaria. La belleza puede, en efecto, subsistir a pesar del desorden, de la desproporción, de la obscuridad en una obra literaria; mientras que la verdad, que es el argumento de la obra científica, exige la transparencia, el orden y la esquemática armonía. Un escritor claro es, sin quererlo, maestro de la ciencia de la verdad, y, por lo tanto, hombre de ciencia. (Marañón, 1969).

4 Gregorio Marañón (1887-1960), médico y escritor de numerosos ensayos como Vida e historia, Ensayo biológico sobre Enrique IV de Castilla y su tiempo o La medicina y nuestro tiempo, entre otros. 
El texto de G. Marañón que presentamos es esencialmente argumentativo dentro de un marco expositivo acompañado de la explicación, que contribuye a clarificar la diferenciación de las dos vertientes de un escritor, la científica y la artística. En principio, Marañón trata de explicar paradójicamente la enorme diferencia existente entre la ciencia y el arte, a la vez que las hace corresponder de forma alternativa poniendo de manifiesto que se complementan por que se exigen mutuamente. Comienza el texto, siguiendo un razonamiento previo, con un conector discursivo adversativo "pero", reforzado con el puntualizador temporal "todavía", para resaltar otra razón mucho más importante para el autor "en las que a mí se me ocurren": "la ventaja del uso literario del lenguaje para lograr la exacta expresión científica". Esta afirmación abre de forma inductiva el texto para el desarrollo argumentativo dialéctico estableciendo la asociación e implicación recíproca de dos términos antagónicos: la ciencia, cuyo objetivo es la exactitud y la verdad, y el arte literario, cuyo objeto es la claridad y la belleza. A partir de ahí, todo el argumentario se centra en explicar y demostrar que, a pesar de las diferencias tan notables entre ambos conceptos, se necesitan mutuamente aunándolos en un solo concepto integrador "literatura científica" para lograr el objetivo principal, considerado como "el gran modelo para la retórica del escritor de oficio" y "el buen escritor".

El desarrollo argumental lo va tejiendo mediante modalidades oracionales asertivas con verbos en $3^{a}$ persona "es evidente que [...]" y estructuras atributivas con el verbo "ser" a modo de definiciones y enumeraciones explicativas: "el arte de la claridad es, por consiguiente, factor científico de primera categoría"/"la verdad, que es el argumento de la obra científica, exige transparencia, el orden y la esquemática armonía", unido a construcciones adjetivas explicativas "que abona la utilidad de la diversión artística en los hombres de ciencia"/"la que obtendrían los hombres de ciencia de una disciplina literaria". El eje principal de la cohesión textual lo proporcionan la repetición léxica alterna de las palabras esenciales y la asociación semántica de términos antagónicos junto a una certera selección de conectores de tipo aditivo "y"/"si es además", explicativo "pues", reforzador argumentativo "se ha dicho y es cierto, y yo lo he repetido muchas veces"/"en efecto", adversativo "pero", intensificador "no es [...] sino", contrastivo "mientras que" y conclusivo "por tanto" e incluso recurre puntualmente a la expresión tautológica "en la ciencia, la forma con que se reviste la verdad forma parte de la verdad misma". Ahora bien, en medio de este discurrir argumental se deja traslucir una crítica clara dirigida tanto al escritor de ciencia "el que escribe obscuramente" y al de literatura "propenso a ser garrulo (tosco) o impreciso". De cualquier forma, el hilo argumentativo sirve para defender su propuesta temática que se concita en la definición del buen escritor "un buen escritor, si es además un 
sabio, posee el instrumento de expresión de su sabiduría". Continúa con el contraste entre el escritor de ciencia y el de literatura, pasando por la necesidad de asumir cada escritor las cualidades de una y otra, hasta lograr el ideal de escritor definido en forma de corolario al final: "Un escritor claro es, sin quererlo, maestro de la ciencia de la verdad, y, por lo tanto, hombre de ciencia". En suma, de todo el razonamiento se infiere que Marañón está pensando y reivindicando la figura del humanista renacentista, que integra las ciencias y las letras.

En cualquier caso, como se ha constatado en el texto de Marañón, al elaborar el discurso académico, hemos de contar, explica van Dijk (1980), con las estructuras gramaticales y las diversas operaciones retóricas, que funcionan como reglas específicas de proyección semántica mediante los procedimientos de supresión, sustitución, permutación y adición. Todas estas operaciones se aplican a estructuras semánticas del discurso académico en forma de resumen, comentario o artículo.

\section{Estrategias pragmáticas en el discurso académico}

Todo discurso, entendido como proceso cognitivo cuyo producto es el texto, se compone, a juicio de Portolés (1998), de una parte gramatical y de otra pragmática en relación con el contexto. Por esta razón, además de recursos lingüísticos y retóricos, la argumentación -ya lo decía Aristóteles - es esencialmente pragmática, puesto que contempla el contexto y la intencionalidad en el discurso. Para él la retórica no utiliza argumentos abstractos frente a la lógica y la dialéctica. No obstante, en la argumentación se recurre a procedimientos dialécticos muy variados, como preguntas retóricas, contrastes, juegos de palabras, condiciones, comparaciones, concatenaciones, correspondencias, anáforas, asociaciones, etc., y otros argumentos destinados a cautivar o refutar al oponente, por ejemplo, tomando como base el discurso del oponente o la utilización de premisas implícitas, que presuponen un elemento sobre el que sus interlocutores no están explícitamente de acuerdo: "Veo que las vacaciones te han sentado bien" (se supone que ha ido de vacaciones).

En el proceso argumentativo son imprescindibles los marcadores del discurso ${ }^{5}$, que sirven para conectar los elementos del discurso y, a su vez, guiar la argumentación hacia la conclusión. Así las relaciones argumentativas se presentan, como refiere Cervera (2013b), por medio de marcas lingüísticas de orientación pragmática y por los topoi (lugares comunes) propios de una comunidad dada. Se distinguen,

5 Para Portolés (1998), los marcadores del discurso "son unidades lingüísticas cuyo significado convencionalmente fijado en la lengua condiciona el procesamiento del discurso en relación con el contexto" (p. 25). 
principalmente, tres tipos de relación conectiva en el discurso escrito, tal como señala Cervera (2013a): conectores, operadores y estructuradores discursivos, cuya función es vincular semántica y pragmáticamente un miembro del discurso con otro anterior con proyección argumentativa, como se muestra en la figura 4.

\begin{tabular}{ll}
\hline -Aditivos: además, encima, aparte, incluso \\
-Distributivos: por un lado, por otro \\
CONECTORES & -Consecutivos: por tanto, por consiguiente, de ahi \\
& -Contrargumentativos: en cambio, por el contrario \\
& -Reformuladores: es decir, con otras palabras \\
\hline -De refuerzo argumentativo: de hecho, desde luego, en efecto (locución de argu- \\
mento probatorio) y en realidad, en el fondo, en otro orden de cosas (locuciones \\
cercanas a la contraargumentación). \\
-De concreción: en particular, en concreto, más aún, precisamente, concretamente, \\
ahora bien, por ejemplo, en este caso \\
-Comentadores: pues, pues bien, asílas cosas \\
-Ordenadores: en primer lugar, en $2^{\circ}$, por una parte, otra \\
-Digresores: por cierto, a todo esto, a propósito
\end{tabular}

Figura 4. Tipos de cohesión discursiva Fuente: Portolés, 2004.

Dentro de cada uno de los tipos de cohesión que aparecen en la figura 4 se incluyen varios subtipos. Todos ellos, con la función específica de cada uno, tienen por objeto relacionar las ideas para lograr la coherencia y la unidad de sentido de los textos. Así los integrantes del grupo de los estructuradores tienen la función de organizar la información para relacionar las ideas desarrolladas, como dice Domínguez (2007), unos, los ordenadores, contribuyen a la integración de las ideas expresadas con distintas funciones de inicio (ante todo, en principio), de continuidad (seguidamente, posteriormente), de enumeración (primero, por último), de reiteración (igualmente, de nuevo) y de ejemplificación (por ejemplo, así, para ilustrar); y otros, los comentadores, explican las razones o causas para asentar las ideas y, por último, los digresores contribuyen a enfocar algún aspecto de interés (por cierto, a propósito) ligado al hilo del tema tratado.

El grupo de los operadores discursivos contribuye a proporcionar información sobre aspectos relacionados con el tema (atendiendo a, en lo tocante a, con respecto a), la fuente (según dice la prensa, de fuentes solventes), el espacio-tiempo (en estas circunstancias, en próximas décadas, en este siglo, en algún lugar), la perspectiva o punto de vista (políticamente hablando) y el componente modal (bien, satisfactoriamente). A su vez, los operadores reforzadores contribuyen a reforzar la clarificación de 
las ideas y los puntualizadores a precisar y matizar (es más, más aún, todavía, menos aún, máxime) los conceptos, las palabras y las explicaciones dadas. Los operadores sirven para presentar los argumentos en forma gradual o escalar (hasta, incluso, ni (siquiera), también y tampoco), al tener la posibilidad de situar en grado extremo una determinada escala argumentativa, al tiempo que funcionan en el discurso como introductores de argumentos que se coorientan con otro anterior para favorecer la conclusión.

El grupo de los conectores contribuye de manera exhaustiva a la cohesión integral de los textos mediante los aditivos o sumativos, que establecen una relación de A + B (y, también, asimismo, también, además) y tienen por objeto mantener la misma relación expositiva, añadir elementos o encadenar enunciados. Suelen aparecer al inicio del $2^{\circ}$ enunciado, pero también en posición inicial, parentética o final de enunciado de modo individualizado o combinados algunos de ellos - por lo tanto, no obstante, en cambio, por otra parte, etc.- con y o pero. El conector aditivo más representativo es $y$, que puede aparecer en posición inicial de enunciado con valor expletivo: "¿Y tu coche?", equivalente a "Y tu coche, ¿dónde lo has comprado?" Pero, normalmente, funciona en coordinaciones de estructura simétrica, como "Salió al balcón y respiró profundamente", o asimétrica, que requiere un orden fijo, como "Sal y̌verás". El valor semántico de y viene dado generalmente por el contexto. Algunos aditivos presentan carácter intensificador, puntualizador y singularizador: es más, más aún, máxime o sobre todo.

Son frecuentes también en el discurso académico los conectores de carácter distributivo para relacionar las partes integrantes del todo mediante la correspondencia o correlación informativa que se establece entre por (de) una parte o un lado/por otra u otro lado. Si aparece el primer elemento, estamos anticipando que hay que poner después un segundo elemento, como en "Podemos hablar de dos posiciones en el tema de las centrales nucleares: por una parte, quienes defienden las centrales por ser seguras y por su potencial energético; $y$, por otra, quienes refutan dichas razones dada la falta de seguridad y la posibilidad de sustituir la producción de energía por energías renovables y no contaminables". Ahora bien, puede aparecer solo la segunda parte de la correlación acompañado de pero, como en "Me ha agradado la reunión; pero, por otra parte, no ha resultado muy provechosa". A los distributivos hay que añadir los reformuladores o explicativos, que son importantes en el discurso académico porque contribuyen a la clarificación y refuerzo de las ideas; dentro de ellos, está la conjunción o, que puede funcionar como conector explicativo, como sinónimo de es decir, y también con valor opcional o alternativo. Asimismo, tienen especial relevancia en el discurso académico los conectores lógicos causativo-consecutivos, puesto que establecen 
una relación argumentativa de causalidad: causa-consecuencia, simbolizada en A>B, forman parte de una demostración. Suelen situarse al principio del enunciado que expresa la consecuencia: pues, por (lo) tanto, por consiguiente, consiguientemente, conque y luego; en consecuencia y de ahí que, por lo que, así pues/así que (coinciden en significado y comportamiento sintáctico, aunque el primero tiene un uso más formal y el segundo se utiliza para mostrar una conclusión derivada de opinión) y para ello establece una relación final o bien proporciona un carácter aseverativo. Asimismo, los conectores de oposición y contraargumentación cumplen un papel esencial en el discurso académico puesto que contribuyen a contrastar pareceres mediante marcas que establecen una relación argumentativa de oposición o contraste, representada por A/B: uno es la contraargumentación, cuando el segundo argumento sirve para cancelar las conclusiones o expectativas deducidas del primero, como en "No me gustan las películas de guerras, pero aun así voy a ver alguna"; y otro es el contraste, que establece una relación comparativa entre dos enunciados cuyos elementos se contraponen sin cancelar ninguna conclusión, como en "Es habitual que empecemos el año con buen humor como hacemos siempre, pero los hechos cotidianos nos llevan a la cruda realidad". La expectativa puede proceder del contenido transmitido o de la situación comunicativa.

Normalmente los conectores argumentativos de carácter opositivo pueden combinarse con y o pero para reflejar o remarcar la oposición. El conector en cambio tiene carácter adversativo o establece una relación comparativa de contraste entre dos enunciados. El conector ahora bien es una expresión que actúa como puntualizador y aunque se adscribe gramaticalmente a las conjunciones adversativas y a las concesivas. Se distinguen tres tipos de relaciones contraargumentativas de acuerdo con la actuación de los conectores opositivos: restrictivo, excluyente y contrastivo.

Una vez que hemos explicado el funcionamiento de los elementos de cohesión discursiva, proponemos un fragmento extraído de Historia como sistema, de Ortega y Gasset $(1975)^{6}$ sobre el concepto de historia para reconocer y explicar cómo contribuyen los conectores discursivos a la organización y coherencia del texto.

Hablo desde el Centro de Estudios Históricos y quiero aprovechar este instante y lugar en que me hallo para manifestar mi entusiasmo y mi fe

6 José Ortega y Gasset (1883-1955), filósofo, orador, historiador y ensayista de obras significativas como La rebelión de las masas, Meditaciones del Quijote, El tema de nuestro tiempo, El espectador o La deshumanización del arte, entre otras muchas. De esa forma, el ensayo se convirtió en un género de referencia en España e Hispanoamérica al dotarlo de sentido crítico y de un estilo literario natural, fluido y ameno cercano al lenguaje de Cervantes. 
en la historia. La historia es hoy para Europa la primera condición de su posible saneamiento y resurgir. Porque cada cual solo puede tener sus propias virtudes y no las del prójimo. Europa es vieja, no puede aspirar a tener las virtudes de los jóvenes. Su virtud es el ser vieja; es decir, el tener una larga memoria, una larga historia. Los problemas de su vida se dan en altitudes de complicación que exigen también soluciones muy complicadas, y estas solo puede proporcionarlas la historia. De otro modo habría un anacronismo entre la complejidad de sus problemas y la simplicidad juvenil y sin memoria que quisiera dar a sus soluciones. Europa tiene que aprender en la historia, no hallando en ella una norma de lo que puede hacer —la historia no prevé el futuro_ sino que tiene que aprender a evitar lo que no hay que hacer; por tanto, a renacer siempre de sí misma evitando el pasado. Para esto nos sirve la historia: para liberarnos de lo que fue, porque el pasado es un revenant y si no se le domina con la memoria, refrescándole, él vuelve siempre contra nosotrosy acaba por estrangularnos. Esta es mi fe, este es mi entusiasmo por la historia y me complace vivamente y siempre ha sido para mí un gran fervor español ver que en este lugar se condensa la atención sobre el pasado, se pasa sobre el pasado, que es la manera de hacerlo fecundo, como se pasa sobre la vieja tierra con el arado e hiriéndola con el surco se la fructifica. (Ortega y Gasset, 1975).

Antes de leer el texto de Ortega y Gasset que presentamos, nos preguntamos ¿por qué subrayamos el conector por tanto? y ¿cómo están organizadas las ideas para lograr la unidad de sentido? Pues bien, observamos que es un texto expositivo-argumentativo, en el que las ideas se presentan de forma ordenada, siguiendo un orden lógico deductivo, propio de un ensayo y también de un texto académico en forma de artículo. Comienza con un enunciado anticipador temático "mi entusiasmo y mi fe en la historia", presentado desde la perspectiva subjetiva y dentro de las coordenadas espaciotemporales en las que se halla el autor. Sigue un enunciado temático nuclear para presentar la tesis: "La historia es hoy para Europa la primera condición de su posible saneamiento y resurgir" $\mathrm{y}$, a partir de ahí, se engarzan enunciados de carácter explicativo-argumentativo, donde dan las razones que justifican el planteamiento, iniciando con el conector discursivo "porque", continuando con el deíctico posesivo "su virtud, su vida" y centrándose en dos palabras esenciales ligadas entre sí "historia" y "Europa", que está dotada de "virtud vieja, de memoria, de historia", en la que se reflejan los problemas de la vida, pero también sus soluciones. Además de establecer 
relaciones de semejanza, continúa con la explicación temática partiendo del conector discursivo "de otro modo" que le sirve para justificar de manera contrastiva lo expresado en el enunciado anterior mediante un enunciado hipotético (o supuesto): "Habría un anacronismo entre la complejidad de sus problemas y la simplicidad juvenil y sin memoria que quisiera da a sus soluciones".

Le sigue un enunciado afirmativo de carácter asertivo, que el autor le proporciona sentido inequívocamente obligativo: "Europa tiene que aprender en la historia", complementado con un enunciado interpolado caracterizador "la historia no prevé el futuro" y acompañado de otro explicativo para reforzar el anterior mediante el uso del conector adversativo-contrastivo: "no hallando en ella una norma [...], sino que tiene que aprender a evitar lo que no hay que hacer", y un conector con apariencia de conclusivo, pero con valor reformulativo "por tanto", equivalente a "es decir". Y termina el texto con una serie de enunciados que enmarcan la conclusión, partiendo del conector conclusivo "para esto", anticipando la finalidad de la historia con un enunciado expresado en estilo indirecto libre con valor asertivo: "Nos sirve la historia (puedo afirmar): para liberarnos de lo que fue", seguido de un enunciado causativo que, a su vez, incluye otro justificativo-condicional. En última instancia, confirma la idea personal planteada al principio mediante un enunciado amplificado en el que reafirma, retomando el pronombre personal de $1^{a}$ persona "yo" y el posesivo "mi", su entusiasmo por la historia, seguido de enunciados coordinados explicativos, estructuras explicativas y comparativas al establecer la analogía entre la historia y la tarea de la labranza de la tierra, que con ella fructifica como la historia que, al conocer el pasado de un pueblo, fecunda.

\section{Conclusión}

La argumentación es una modalidad esencial en cualesquiera producciones del discurso académico en español. La presencia de la argumentación en el discurso escrito se muestra a través mecanismos e indicadores que permiten conocer la textualización, la intertextualidad y la polifonía discursiva de los enunciadores ${ }^{7}$ como explica Ducrot (1996), a los que da voz el locutor. El discurso académico ha de ser esencialmente argumentativo que permita explicar la importancia de la cuestión temática antes de la formulación de hipótesis. Así, al escribir académicamente un tema, hemos de informarnos y documentarnos previamente y, a continuación, debemos partir de

7 Para para Ducrot (1996), los enunciadores, son los sujetos de los enunciados a través de las citas o del discurso directo o indirecto que muestran las diferentes voces a las que da entrada un locutor en el proceso discursivo para ofrecer sus puntos de vista. 
un plan en el que haya una línea argumental dentro de un marco expositivo. Este plan ha de estar integrado por una introducción breve y clara sobre el tema que incluya la formulación de hipótesis, siguiendo con la propuesta de la tesis mediante una afirmación para saber qué se va a defender. Sigue el cuerpo argumentativo con argumentos o razonamientos lógicos en párrafos debidamente cohesionados por medio de recursos lingüístico-retóricos y estrategias pragmático-discursivas, que lleven a una conclusión válida, donde se sintetizan los resultados y se sugieren nuevas propuestas.

En el análisis aplicado al grupo de textos hemos comprobado que la argumentación es una forma de expresión prototípica de organización discursiva, en línea con Verlich (1979 y Adam (1992). Además, en ellos se presenta un desarrollo organizativo lógico y conceptual mediante la argumentación, la explicación y la descripción. Este aspecto pone los ensayos analizados en consonancia con los géneros académicos que, a juicio de Montolío (2002), facilitan la consecución del objetivo básico de transmitir información de carácter científico técnico de forma precisa, clara y objetiva. Más aún, puntualiza Vázquez (2001), "además de ser expositivos, los textos académicos son frecuentemente polémicos en los cuales la persona que escribe opone su opinión a la opinión de otras personas" (p. 41), contando con que en la exposición hay un razonamiento lógico al dar cuenta de conocimientos y con que una de las características de los géneros académicos, compartida con el ensayo, es la argumentación explícita. Otro de los aspectos obtenidos de los textos analizados ha sido la coincidencia en todos ellos en utilizar los recursos lingüísticos mediante el establecimiento de relaciones de condición, causa-consecuencia, alternancia de términos, recurrencia léxica, etc.; de procedimientos retóricos adecuados como la metáfora, la correspondencia conceptual, la comparación, la asociación semántica, el contraste, la analogía, la enumeración, etc.; y las estrategias pragmático-argumentativas mediante la definición, ejemplificación, generalización, las referencias, las citas, etc., que constituyen los elementos de cohesión requeridos para lograr la coherencia, la adecuación y la unidad de sentido global.

A partir de la metodología empírica aplicada, resaltamos que los textos analizados son piezas de ensayo cuyos contenidos están bien construidos y argumentados por su pertinencia, validez y fuerza argumental. Aun así, hallamos alguna diferencia ligada al enfoque, de forma que el ensayo más objetivo es el texto de Lugo Hubp que versa sobre la evolución de la cartografía por el dominio de la $3^{a}$ persona verbal, la modalidad oracional enunciativa, la presencia del discurso directo en las citas y el mayor rigor científico. Los otros tres se diferencian entre sí: el de Larra, construido aparentemente de modo objetivo, contiene un sentimiento hondamente subjetivo; en 
cambio, los de Marañón y Ortega y Gasset reflejan explícitamente una opinión con el "yo" recurrente, pero del proceso desarrollado el lector deduce un pensamiento objetivo. Así pues, esta investigación nos ha servido para mostrar que el ensayo es el género discursivo prototípico para desarrollar las competencias lingüístico-cognitivas en el proceso que lleve a los estudiantes desde la lectura comprensiva de textos ajenos representativos a la producción de textos propios.

\section{Referencias}

Adam, J. M. (1992). Élements de linguistique textuelle. Mardaga.

Álvarez, M. (1997). Tipos de escritos II. Exposición y argumentación. Arco Libros.

Anscombre, J.C. y Ducrot, O. (1994). La argumentación en la lengua. Gredos.

Aristóteles. (1997). Retórica. Instituto de Estudios Políticos.

Beaugrande, R. y Dressler, W. U. (1997). Introducción a la lingüística del texto. Ariel.

Calsamiglia, H. y Tusón, A. (1999). Las cosas del decir. Manual de análisis del discurso. Ariel.

Carrillo Guerrero, L. (1997). Argumentación y argumento. Signa: Revista de la Asociación Española de Semiótica, (16) 289-320. https://dialnet.unirioja.es/servlet/articulo?codigo=2216764

Cervera Rodríguez, Á. (2019). Indicadores pragmático-argumentativos en el ensayo contemporáneo en A. Cervera y A. Hernando, Análisis del discurso en el español contemporáneo (pp.1939). Visor.

Cervera Rodríguez, Á. (2013a). Los enunciados del español en el discurso oral y escrito. Editorial Clásicas del Orto.

Cervera Rodríguez, Á. (2013b). Marcas lingüísticas de orientación argumentativa en actos de habla del español en J. A. Mayoral, Lingüística, retórica y teoría de la literatura (pp. 57-70). Arco libros.

Cervera Rodríguez, Á., Hernández, G., Pichardo, C. y Sánchez Lobato, J. (2007). Saber escribir. Aguilar.

Cuenca, M. J. (1995). Mecanismos lingüísticos y discursivos de la argumentación. Comunicación, lenguaje y educación, 25, 23-40. 
De Larra, M. J. (2000). Fígaro. Colección de artículos dramáticos, literarios, políticos y de costumbres. Crítica.

Ducrot, O. (1996). El deciry lo dicho. Paidós.

Domínguez García, M. N. (2007). Conectores discursivos en textos argumentativos breves. Arco libros.

Gallardo, S. (2005). La monografía universitaria como aprendizaje para la producción de artículos científicos en G. Vázquez (coord.), Español con fines académicos: de la comprensión a la producción de textos (pp.13-28). Edinumen.

Jakobson, R. (1975). Ensayos de lingüística general. Seix Barral.

Lo Cascio, V. (1998). Gramática de la argumentación: estrategias y estructuras. Alianza.

Los motivos para abaratar el despido. (2018). Libremercado. Recuperado el 23 de mayo de 2019 de: www.libremercado.com

Lugo Hubp, J. (2016). La superficie de la tierra II. Procesos catastróficos, mapas. El relieve mexicano. Fondo de Cultura Económica

Marafioti, R. (2005). Los patrones de la argumentación. La argumentación en los clásicos y en el siglo XX. Biblos.

Marañón, G. (1969). La medicina y nuestro tiempo. Espasa Calpe. Austral.

Marimón Llorca, C. (2006). El texto argumentativo. Liceus. Biblioteca de recursos electrónicos de humanidades. E-excelence. https://vdocuments.site/el-texto-argumentativo-56290b2f427dc. html [15/10/2019]

Moeschler, J. (1985). Argumentation et conversation. Hatier-Crédif.

Montolío, E. (coord.). (2002). Manual práctico de escritura académica (vol. II). Ariel.

Ortega y Gasset, J. (1975). Historia como sistema. Revista de Occidente. El Arquero.

Perelman, C. y Olbrechts-Tyteca, L. (1994). Tratado de la argumentación. La nueva retórica. Gredos.

Plantin, C. (1990). Essais sur l'argumentation. Introduction linguistique a l'étude de la parole argumentative. Kimé. 
Plantin, C. (1998). La argumentación. Ariel.

Portolés, J. (1998). Marcadores del discurso. Ariel.

Ribas, M. (2002). De la explicación a la argumentación. Textos de didáctica de la lengua y la literatura, (29), 11-20. Grao.

Salinas, P. (1992). Defensa del lenguaje. Alianza Editorial.

Toulmin, S. E. (1958). The uses of argument. University Press.

Van Dijk, T.A. (1983). La ciencia del texto. Paidós.

Van Dijk, T.A. (1980). Estructuras y funciones del discurso. Siglo XXI.

Van Eemeren, F., Grootendorst, R. Henkemans, F y Marafioti, R. (2006). Argumentación: análisis, evaluación y presentación. Editorial Biblos.

Vázquez, G. (coord.). (2001). Guía didáctica del discurso académico escrito. ¿Cómo se escribe una monografía? Edinumen.

Vázquez, G. (coord.). Español con fines académicos: de la comprensión a la producción de textos. Edinumen.

Vignaux, Georges (1986). La argumentación. Ensayo de lógica discursiva. Buenos Aires: Hachette.

Werlich, E. (1979). Typologie der Texte. Quelle \& Meyer.

Weston, A. (2004). Claves de la argumentación. Ariel. 